\title{
O QUE PENSA UM GRUPO DE LICENCIADOS SOBRE A PRÁTICA DA EDUCAÇÃO AMBIENTAL NO CONTEXTO ESCOLAR?
}

\author{
Diego Machado Ozelame ${ }^{1}$ \\ Mônica da Silva Gallon ${ }^{2}$ \\ João Bernardes da Rocha Filho ${ }^{3}$
}

\begin{abstract}
Resumo: Este artigo objetiva compreender as concepções relacionadas às vertentes da EA, conservadora e crítica, a partir da descrição de práticas realizadas por um grupo de licenciados, ingressantes em um curso de pós graduação, na área de Ensino de Ciências e Matemática Utilizou-se um questionário para a coleta dos dados, elegendo à analise deste estudo a seguinte questão: "Como exemplo, narre alguma situação da sua experiência como professor (a) ou como aluno (a) que mostre relação com a Educação Ambiental”. As respostas compuseram o corpus de análise desse estudo. O processamento dos dados foi realizado por meio da Análise Textual Discursiva. Constatou-se um predomínio pela concepção conservadora frente à EA, evidenciadas pela maneira fragmentada que os entrevistados pensam a temática. Diante da discussão produzida, entende-se que o enfrentamento deste obstáculo é possível mediante uma mudança na forma como o professor compreende e dimensiona o problema da EA, uma vez que reflete na sua prática pedagógica. Concluímos que a ação mais efetiva é ressignificar o entendimento e a forma como os professores dimensionam sua relação com as práticas relacionadas à EA.
\end{abstract}

Palavras-chave: Educação Ambiental. Prática Pedagógica. Projetos Escolares.

\section{WHAT DO A GROUP OF GRADUATES THINK ABOUT THE PRACTICE OF ENVIRONMENTAL EDUCATION IN THE SCHOOL CONTEXT?}

\begin{abstract}
This article discusses actions related to Environmental Education (AE) in the understanding of a group of graduates entering a postgraduate program in the area of Science and Mathematics teaching on teaching practice. The objective was to identify the graduates' conceptions on the theme. A questionnaire was used to collect the data, whose answers made up the corpus of analysis of this study. Data processing was performed through Discursive Textual Analysis. In view of the data analysis, there was a predominance of the conservative conception in relation to $A E$, evidenced by the fragmented way that the interviewees think about the theme. In view of the discussion produced, we understand that coping with this obstacle is possible through a change in the way the teacher understands and measures the problem of $A E$, as it reflects on his pedagogical practice. We conclude that the most effective action is to reframe the understanding and the way teachers measure their relationship with practices related to $A E$.
\end{abstract}

Key words: Environmental Education. Educational Practice. School Projects

\section{QUÉ PIENSA UN GRUPO DE GRADUADOS SOBRE LA PRÁCTICA DE LA EDUCACIÓN AMBIENTAL EN EL CONTEXTO ESCOLAR?}

\begin{abstract}
Resumen: Este artículo aborda acciones relacionadas con la Educación Ambiental (EA) en la comprensión de un grupo de graduados que ingresan a un programa de posgrado en el área de la enseñanza de Ciencias y Matemáticas en la práctica docente. El objetivo era identificar las concepciones de los graduados sobre el tema. Se utilizó un cuestionario para recopilar los datos, cuyas respuestas constituyeron el corpus de análisis de este estudio. El procesamiento de datos se realizó através del Análisis Textual Discursivo. En vista del análisis de datos, hubo un predominio de la concepción conservadora en relación con la EA, evidenciada por la forma fragmentada en que los entrevistados piensan sobre el tema. En vista de la discusión producida, entende-se que enfrentar este
\end{abstract}

\footnotetext{
${ }^{1}$ Doutor em Ensino de Ciências e Matemática pela Universidade Estadual de Londrina (UEL). Mestre em Educação em Ciências e Educação Matemática pela Pontifícia Católica Universidade do Rio Grande do Sul (PUC/RS). Graduado em Ciências Biológicas pela Universidade de Caxias do Sul (UCS).

${ }^{2}$ Doutora e Mestra em Educação em Ciências e Educação Matemática pela Pontifícia Católica Universidade do Rio Grande do Sul (PUC/RS). Graduada em Biologia (UNISINOS) e Pedagogia (UNINTER). Professora da rede municipal de Canoas/RS.

${ }^{3}$ Doutor em Engenharia Mecânica pela Universidade Federal de Santa Catarina (UFSC). Mestre em Educação pela Pontifícia Católica Universidade do Rio Grande do Sul (PUC/RS). Graduado em Física pela (PUC/RS), Matemática pela Claretiano Centro Universitário e Filosofia pela Universidade do Sul de Santa Catarina (UNISUL). Professor do PPG de Educação em Ciências e Matemática (PUC/RS).
} 
obstáculo es posible a través de un cambio en la forma en que el maestro entiende y mide el problema de la EA, ya que se refleja en su práctica pedagógica. Conclui-se que la acción más efectiva es reformular la comprensión y la forma en que los maestros miden su relación con las prácticas relacionadas con la EA.

Palabras llave: Educación Ambiental. Práctica Pedagógica. Proyectos Escolares.

\section{Introdução}

Educação Ambiental (EA) é um termo historicamente atribuído às práticas educativas relacionadas ao meio ambiente. Atualmente, reconhece-se a necessidade dessas práticas nos mais diversos espaços sociais, seja por meio da educação formal ou não-formal. A busca por uma visão globalizadora com o enfoque na solução de problemas fez com que a temática ambiental ganhasse força nas discussões dos últimos anos, refletindo nos debates realizados nas escolas.

Para Brügger (2004, p. 83), “o surgimento de uma Educação Ambiental pressupõe o reconhecimento de que a educação tradicional não tem sido ambiental”. O olhar fragmentado às diversas áreas que compõem o currículo escolar, a formação docente que pouco contempla aspectos ambientais e uma sociedade tecnicista, favorecem o cenário para que a abordagem ambiental seja mencionada como mais um tópico nos currículos escolares conteudistas.

A EA no cenário educacional brasileiro se faz presente a partir da Constituição Federal de 1988, que estabelece como dever do Estado a sua promoção em todos os níveis de ensino. O tema passa a integrar as Diretrizes e Bases da Educação Nacional - Lei 9.394/1996) (BRASIL, 1996) - e, mais tarde, com a Lei nº 9.795/99 - Política Nacional de Educação Ambiental - PNEA (BRASIL 1999) -, em que fica estabelecido que a EA seja um componente essencial e permanente da educação em todo o país. De acordo com as Diretrizes Nacionais da Educação Básica - DCNEB (BRASIL, 2013) -, a EA deve estar presente, de forma articulada e integrada, em todos os níveis e modalidades do processo educativo, abrangendo as instituições públicas e privadas, em caráter formal e não-formal de forma contínua e permanente, não constituindo uma disciplina isolada.

As DCNEB (BRASIL 2013, p. 550) sugerem que a abordagem curricular da EA ocorra de maneira "integrada e transversal, inter, multi e transdisciplinar, contínua e permanente em todas as áreas do conhecimento, componentes curriculares e atividades escolares e acadêmicas". O documento aponta que a transversalidade deve ser compreendida "como uma forma de organizar o trabalho didático-pedagógico em temas em que eixos temáticos são integrados às disciplinas e às áreas ditas convencionais de forma a estarem presentes em todas elas" (BRASIL, 2013, p. 67).

As diretrizes diferenciam a transversalidade da interdisciplinaridade, tomando como ponto de partida a incompletude da realidade. Destaca-se ainda que a "transversalidade se refere à dimensão didático-pedagógica, e a interdisciplinaridade, à abordagem epistemológica dos objetos de conhecimento" (BRASIL, 2013, p. 67). A interdisciplinaridade, conforme o 
documento (BRASIL, 2013, p. 28), prevê a "transferência de métodos de uma disciplina para outra”. Sendo assim, é possível afirmar que a transversalidade somente se realiza de modo apropriado dentro de concepções epistemológicas como a interdisciplinaridade, uma vez que a dimensão didático pedagógica reflete as concepções epistemológicas do professor.

A Base Nacional Comum Curricular (BNCC) documento mais recente que versa sobre a organização curricular no Brasil (BRASIL, 2017), apresentava em suas versões preliminares um amplo destaque à EA, principalmente no texto contido na segunda versão. A terceira e última versão, traz uma certa invisibilidade às questões ambientais. Conforme constatado por Behrend, Cousin e Galiazzi (2018), o termo Educação Ambiental aparece somente em uma passagem em todo o documento. De acordo com Andrade e Piccinini (2017), a insignificante participação da EA na BNCC se deve a escolhas políticas centradas no atual cenário do país.

A EA e sua inserção na educação formal, não preconiza um conteúdo estanque a ser trabalhado em um ou outro componente curricular. Os temas abordados emergem do cotidiano e as relações são estabelecidas com o conteúdo escolar, na medida em que o professor identifica essa necessidade. Partindo dessas interpretações, abre-se espaço à transversalidade dos temas ambientais, perpassando o currículo escolar e avançando para um olhar mais global aos problemas atuais.

A abordagem de temas transversais é favorecida por meio da realização de práticas interdisciplinares, facilitando a compreensão dos estudantes, pois permite uma conexão do assunto do cotidiano com as disciplinas escolares (BRASIL, 2013). Além disso, a escolha de temas prioritários geralmente emerge de informações locais ou noticiadas na mídia, despertando o interesse do estudante, o que permite a sua participação elegendo o que é prioritário à discussão em sala de aula.

Os temas transversais conferem um sentido social aos conteúdos conceituais nas diversas áreas do conhecimento, assim, transcendem o aprender apenas pela necessidade informativa (ALMEIDA, 2006). Nessa perspectiva, a EA como tema transversal tem por objetivo transpor as barreiras disciplinares, e gerar um livre trânsito entre todas elas. Sobre esta integração, Borges, Basso e Rocha Filho (2008) mencionam que isto não deve ser uma imposição, porém, manifestado mais como uma atitude, buscando preencher as lacunas da excessiva prática disciplinar em sala de aula, a partir do trabalho cooperativo. Esta proposta integradora pode ser concebida como um movimento de ensino mais sociológico, uma vez que correspondem às mudanças que ocorrem na sociedade, dadas as proporções dos riscos dessa tentativa de transposição didática (RICARDO, 2008).

A EA apresenta diferentes compreensões e, de acordo com Sauvé (2005), possui cerca de quinze correntes de pensamento e formas de ação, divididas em dois eixos principais de discurso: 
um conservador e outro emancipatório (LIMA, 2002; LOUREIRO, 2004). A vertente conservacionista percebe o ambiente como fonte de recursos e, nessa ótica, adota comportamentos e ações direcionadas a projetos de conservação, protegendo a natureza de intervenções humanas (CARVALHO, 2012). Guimarães (2004b) defende que esta corrente está inclinada em manter o modelo atual de sociedade e sua visão com relação ao meio ambiente. Em contraponto, a EA crítica concebe o ambiente como objeto de transformação, desconstruindo as realidades socioambientais na busca de transformar a fonte dos problemas a partir de análise de discurso, estudos de caso, debates e pesquisa-ação (SAUVÉ, 2005). Esta visão se mostra comprometida com mudanças no modelo hegemônico de sociedade almejando justiça social e igualdade (GUIMARÃES, 2004b).

Conforme Carvalho (2012, p. 37),

A EA surge em um terreno marcado por uma tradição naturalista. Superar essa marca, mediante a afirmação de uma visão socioambiental, exige um esforço de superação da dicotomia entre natureza e sociedade, para poder ver as relações de interação permanente entre a vida humana social e a vida biológica da natureza.

$\mathrm{Na}$ trajetória histórica da EA a visão conservadora marca a origem de movimentos ambientais e ações ligadas à educação, de forma um pouco ingênua e marcada por ações desarticuladas, muitas vezes não atingindo o público alvo dos programas. A medida em que surge uma noção de que não é possível dissociar a sociedade e ambiente, as buscas por transformações passam a ser pautadas pela criticidade, e tendem a busca não de soluções simplistas, mas que atendam às necessidades da população e da natureza.

As DCNEB esclarecem que para a compreensão do documento "concebe a Educação Ambiental na perspectiva socioambiental, da justiça ambiental, das relações equilibradas e das concepções de sustentabilidade" (BRASIL, 2013, p. 542). Neste sentido, os problemas socioambientais, sejam eles locais ou globais, estão conectados, não podendo ser analisados como aspectos isolados, pois são manifestações de um modelo de sociedade - consumista, individualista, antropocêntrica - e, portanto, assim devem ser percebidos também pelos educadores (GUIMARÃES, 2007). Para Behrend, Cousin e Galiazzi (2018), uma visão mais conservadora parece ser a sustentada pela BNCC em sua versão final (BRASIL, 2017). Constatase que há concepções sobre a EA divergentes nos documentos em vigor e que regem a educação no Brasil. Porém, em consonância à preocupação global com as questões que envolvem o meio ambiente, a degradação ambiental e o papel de cada cidadão nessa trajetória, torna-se essencial o debate nas escolas, não somente quanto às questões ambientais, mas também questões políticas implícitas nesse processo. As ideias apresentadas tanto nas DCNEB quanto na BNCC servem 
como embasamento para a construção dos Projetos Políticos Pedagógicos das escolas, bem como na elaboração dos planos de estudo e na abordagem realizada pelos docentes em sala de aula. Sabe-se que todo currículo apresenta uma intencionalidade, na qual estão baseadas as escolhas do que deve ou não integrá-lo. Portanto, nenhum currículo é neutro ou ingênuo (MOREIRA; TADEU, 2011). Neste sentido é relevante uma análise de como professores em atuação compreendem a EA, sendo que estas podem praticasse manifestar em suas práticas pedagógicas.

O objetivo desta pesquisa foi compreender as concepções relacionadas às vertentes da EA, conservadora e crítica, a partir da descrição de práticas realizadas por um grupo de licenciados, ingressantes em um curso de pós graduação. A seguir são apresentados os procedimentos metodológicos desta pesquisa.

\section{Procedimentos Metodológicos}

Este estudo integrou as atividades propostas por uma disciplina de um curso de pósgraduação stricto sensu, em ensino de Ciências e Matemática, oferecido em uma universidade privada no sul do Brasil. O grupo de participantes - ingressantes no curso de mestrado constituiu-se de 24 licenciados das áreas da Matemática, Biologia, Física, Pedagogia e Educação Física; sendo 16 do gênero feminino e 8 do gênero masculino, com idades entre 22 e 48 anos. Desses, 16 participantes estavam em exercício de atividade docente. Destes participantes, dois possuíam especialização em EA. Por questões éticas de pesquisa, optou-se por manter o anonimato dos participantes, os (as) quais serão designados por letras maiúsculas.

Para coleta de dados foi utilizado um questionário, com perguntas dissertativas, sendo que para este estudo foi elegida à análise da seguinte sentença: Como exemplo, narre alguma situação da sua experiência como professor (a) ou como aluno (a) que mostre relação com a Educação Ambiental. Os questionários foram respondidos e entregues via e-mail ao docente responsável pela disciplina.

As respostas obtidas dos questionários compuseram o corpus de análise desta investigação, utilizando-se a metodologia de Análise Textual Discursiva - ATD (MORAES; GALIAZZI, 2013). De acordo com esta ferramenta analítica, o corpus de análise (neste caso, todas as respostas dos pós-graduandos relacionadas à pergunta quatro do questionário) necessita de uma leitura intensa e cuidadosa - o que os autores chamam de impregnação (MORAES; GALIAZZI, 2013), seguida da fragmentação das ideias fornecidas pelos depoentes - cada uma delas resultou em uma unidade de sentido. Essas unidades ganham uma codificação, de acordo com o participante (neste caso, optou-se por uma letra) e com a ideia (um número). Posteriormente, as unidades de sentido são agrupadas conforme semelhança em seu conteúdo constituindo uma categorização, sendo esse processo repetido até a obtenção de categoriais 
finais. A categorização pode ocorrer por meio de categorias pré-determinadas pelo pesquisador (a priori) ou categorias emergentes. Neste estudo, optou-se por categorias determinadas a priori. Ao final deste processo, o pesquisador necessita transformar os dados categorizados em metatextos, um processo de escrita que envolve o olhar do pesquisador sobre as respostas embasado em outros autores, buscando assim a "emergência do novo" (MORAES; GALIAZZI, 2013, p. 215, grifo dos autores), algo além do que foi dito ou encontrado no corpus de análise. Preferiu-se ao apresentar as falas dos participantes da pesquisa, colocá-las na íntegra, a fim de facilitar a compreensão da ideia pelo leitor.

\section{Resultados e discussão}

As análises dos dados obtidos foram organizadas em duas categorias selecionadas a priori: Projetos inseridos no cotidiano escolar e Projetos e atividades pontuais de EA no ambiente escolar. Passa-se a descrever o conteúdo dessas categorias.

\section{Projetos inseridos no cotidiano escolar}

Esta categoria abrange a descrição dos participantes de trabalhos desenvolvidos por eles em sala de aula com algumas turmas e também a seu engajamento em projetos maiores, envolvendo toda a escola. Foram apontados pelos mestrandos, como exemplos de projetos desenvolvidos de maior abrangência foi mencionada a produção de hortas, conforme relatados pelos sujeitos A e D:

Ao trabalhar alimentação saudável, preservação ambiental e qualidade de vida, planejamos construir uma horta junto aos alunos e dela se alimentar, procurando fazer com que a turma percebesse a importância destes assuntos trabalhados em sala de aula no cotidiano da escola e da família (PARTICIPANTE A).

Outro exemplo de atividade é a realização da horta na escola, tendo os alunos os responsáveis pelo plantio, colheita e destinação à comunidade dos produtos cultivados (PARTICIPANTE D).

A realização destes projetos permitiu atividades que envolvessem a comunidade, aproximando-a da escola e, além disso, propiciou a discussão em sala de aula de temas como a alimentação saudável e a preservação ambiental. Essa abordagem que aproxima os diferentes atores da escola faz com que a aprendizagem proporcionada tenha mais significado ao estudante, uma vez que integra sua realidade. Conforme Freire (1996), é necessário não apenas respeitar os saberes que os educandos possuem, aprendidos em outros contextos sociais além da escola saberes estes constituídos nas práticas sociais - mas, sobretudo, discuti-los e confrontar suas relações com os conteúdos ditos formais vistos no cotidiano escolar. 
Outro assunto debatido sob molde de projeto foram os resíduos sólidos recicláveis, dos quais emergiram propostas envolvendo a construção de uma casa sustentável e a reutilização de materiais na elaboração de instrumentos para aulas do componente curricular de Matemática. Sobre isso, participante $\mathrm{C}$ afirma:

Prosseguindo, construímos um teodolito (instrumento que mede ângulos) utilizando somente materiais recicláveis e reaproveitando materiais como papelão, plástico, canudos, enfim, realizamos uma atividade prática bastante construtiva, onde os alunos se envolveram tanto na Matemática como na importância de reaproveitar materiais (PARTICIPANTE C).

Os participantes relataram a realização de trabalhos com uma perspectiva interdisciplinar, a partir de assuntos abordados em sala de aula, tais como o consumo de energia elétrica de cada família da turma envolvida, o consumo consciente de água e presença de coleta seletiva na comunidade escolar.

No projeto do uso de energias renováveis, solicitei aos alunos que trouxessem uma conta de energia elétrica de casa e uma relação dos aparelhos elétricos que possuíam com o tempo em média de uso dos mesmos. Expliquei o que era eficiência energética, qual sua importância, qual o consumo médio dos aparelhos que eles tinham em casa e como era feita a cobrança da energia elétrica (PARTICIPANTE J).

É perceptível nos relatos dos participantes que, apesar de estarem inseridos no contexto de estudo, não está destacada problemática ambiental de fato. As atividades descritas conduzem a uma ideia de simples cumpridoras da transmissão de tópicos relacionados à EA em uma linha conservacionista (JACOBI 2005, LAYRARGUES, 2006). Desta forma leva os participantes das atividades à compreensão de um e compreendendo um ambiente como um recurso a ser preservado desconsiderando o ser humano como parte deste.

Os temas exemplificados pelos participantes da pesquisa permitem conexões interdisciplinares, transitando livremente entre conteúdos trabalhados e/ou pensados por estes licenciados, como também por problemáticas que possivelmente atravessam a vida dos estudantes. Estas abordagens oportunizam um elo entre as diferentes áreas do conhecimento e os saberes que os estudantes já adquiriram ao longo de suas vidas. Isso vai ao encontro ao trecho da DCNEB (BRASIL, 2013), referente ao Ensino Médio, em que evidencia a interdisciplinaridade como forma de contribuir ao estudante uma formação que o permita a análise, a explicação à prevenção e intervenção na resolução de questões do seu cotidiano ou no desenvolvimento de projetos que propiciem ação e/ou investigação.

Os temas relacionados ao meio ambiente são favorecidos quando abordados em uma perspectiva interdisciplinar, por meio de parcerias entre professores na escola ou 
individualmente. Concorda-se com Brügger (2004, p. 95, grifos da autora) deque é possível a realização de um bom trabalho com caráter interdisciplinar realizado por mesmo professor, "pois a condição sine qua non é na verdade uma visão interdisciplinar por parte de cada pesquisador”.

Outro exemplo de atividade descrita pelos participantes é a criação e manutenção de um blog na internet, elaborado por uma professora e um grupo de estudantes de diversas séries/anos, cujo objetivo central foi apontar os problemas ambientais enfrentados pela comunidade escolar e possíveis soluções que os estudantes podiam perceber. Os educandos realizaram entrevistas com os colegas e com a comunidade de entorno da escola, além disso, registraram as informações a partir de fotos e reportagens retiradas da mídia. O blog foi divulgado na comunidade escolar, recebendo críticas e elogios que serviram para as próximas ações do grupo. Trata-se de uma proposta interdisciplinar em que se percebe a reflexão dos estudantes envolvidos e as construções ocultas do currículo, dando voz aos sujeitos, considerando seus contextos. Este tipo de estratégia aproxima o estudante da realidade local e dá a ele a noção de pertencimento, fazendo-o refletir sobre os problemas de sua comunidade como algo passível de modificação e que ele pode ser o protagonista dessas mudanças. Aqui, percebe-se nesta ação uma aproximação com a EA com viés crítico. Isso reforça o que Carvalho (2012, p. 67), apresenta como a formação do sujeito ecológico, sendo este "um sujeito ideal que sustenta a utopia dos que creem nos valores ecológicos, tendo, por isso, valor fundamental para animar a luta por um projeto de sociedade bem como a difusão desse projeto". Em outras palavras, a autora sugere que não se trata de um sujeito em busca de um modelo ideal, mas sim de um indivíduo com postura crítica ao modelo atual de exploração ambiental, bem como de desigualdade e exclusão social.

\section{Projetos e atividades pontuais de EA no ambiente escolar}

Nesta categoria foram reunidas as unidades de significado que abordaram os projetos e atividades envolvendo práticas relacionadas à EA, executados de forma pontual e/ou desconectados de outras ações dentro do ambiente escolar. Os projetos abarcados nesta categoria se diferem dos descritos na categoria anterior, os quais foram desenvolvidos ao longo de um determinado período e envolviam avaliações e interlocuções com diferentes componentes curriculares e conteúdos relatados pelos participantes da pesquisa.

Nas falas dos participantes incluídas nesta categoria, evidencia-se uma EA pautada na realização de projetos ocasionais, na implementação de projetos impostos pela escola ou pelas secretarias de educação, incluindo-se também a execução de atividades isoladas - visitas de campo e/ou palestras - utilizadas como ferramentas para promoção da EA. Foram descritas pelos participantes em alguns dos relatos a participação ou organização de projetos envolvendo a EA de forma isolada de outras atividades desenvolvidas pelo depoente ou pela escola onde este 
trabalha. As temáticas das atividades elencadas por estes professores foram: água, energia e alimentação. Também ficaram bastante evidentes assuntos referentes ao descarte de resíduos domésticos e suas implicações, principalmente relacionados à reciclagem e a reutilização de materiais. Sobre isso, apresenta-se alguns depoimentos:

Ao trabalhar com trigonometria, iniciei problematizando sobre a importância da reciclagem com os alunos. Assim, iniciamos uma discussão onde os alunos trouxeram suas vivências relacionadas ao assunto (PARTICIPANTE L).

O homem num sentido geral não se dá conta que também é responsável pelo ambiente em que vive, então procuro sempre fazer reflexões com meus alunos sobre atitudes do cotidiano, que por muitas vezes sem perceber, são atitudes que prejudicam o meio ambiente. Atitudes como, por exemplo: - jogar lixo no chão, comprar animais silvestres, desperdício de água, e o impacto ambiental que estas atitudes causam (PARTICIPANTE M).

Identificou-se nos depoimentos uma tendência à realização de capacitações envolvendo a temática sobre a reciclagem de resíduos sólidos, sendo estas direcionadas aos docentes. Estas iniciativas são geralmente oferecidas por secretarias municipais de meio ambiente ou educação, por organizações não governamentais ou pela iniciativa privada. Geralmente após estes cursos de capacitação, ocorre a aplicação das práticas aprendidas em grande escala, disseminadas nas escolas de atuação dos participantes, fato que pode estar refletindo nas ações no âmbito escolar e justifica a grande frequência da temática nos relatos.

Práticas voltadas ao reuso e reciclagem de resíduos sólidos realizadas de maneira pontual e/ou descontextualizadas caracterizam uma EA com viés mais conservador. A iniciativa para elaboração de projetos com esse caráter pode partir de diferentes esferas, como relatado pelos participantes da pesquisa: do professor, da escola, das secretarias de educação e/ou meio ambiente. Exemplo disso, foi observado no discurso do sujeito a seguir:

Na minha escola fizemos um projeto de coleta de lixo. Os alunos deveriam separar o lixo seco em casa e em um dia combinado este lixo era levado para escola, pesado e vendido. $O$ aluno que levasse a maior quantidade ganharia um prêmio (PARTICIPANTE N).

Projetos como estes, verticalizados, onde há claramente um elaborador e um cumpridor agregam pouco ou nenhum aprendizado, tornando-se apenas um produto mercantilista. A geração de renda por meio de projetos escolares é bastante questionável, visto que, embasandose em uma ação que deveria visar o cuidado e desestimular o consumo de recursos, pode estar provocando efeito reverso. Esse modelo de ação é característica de um modelo conservador e descontextualizado de EA, conforme afirma (JACOBI, 2005) 
[...] a abordagem conservadora, pautada por uma visão reformista, propõe respostas instrumentais. Observa-se, de fato, que o modus operandi que predomina é o das ações pontuais, descontextualizadas dos temas geradores, frequentemente descoladas de uma proposta pedagógica, sem questionar o padrão civilizatório, apenas realimentando uma visão simplista e reducionista (JACOBI, 2005, p. 244).

Brügger (2004, p. 98) também faz críticas sobre esse tipo de proposta, alegando que trabalhos mal conduzidos ou sem um objetivo claro, principalmente com relação a quem se deseja atingir com a proposta, podem ser ainda mais desastrosos do que a não abordagem: "vão aprender desde cedo a confundir meio ambiente com natureza; problemas ambientais relacionados à poluição; e desenvolvimento sustentável com preservação de potenciais produtivos dos ecossistemas". A autora trata sobre importância de ser ter clareza sobre o que está implícito nos currículos escolares ao se abordar a EA, constituindo o currículo oculto, pois ideologicamente os sujeitos favorecidos em meio aos discursos e materiais estudados podem não ser aqueles para os quais as aulas estão sendo ministradas. Brügger (2004) exemplifica a exposição com a questão dos 3Rs: Reduzir, Reutilizar e Reciclar, pois há um apelo muito grande por parte da indústria, da mídia e da escola, em detrimento dos outros dois $R s$ (Reduzir e Reutilizar), que deveriam desencorajar o consumo desenfreado e expor que nem todo material pode ser reciclado eternamente. Desta forma "a reciclagem é, portanto, uma bandeira forte no setor empresarial porque a implementação dos dois primeiros 'Rs' seria desastrosa economicamente, dentro da lógica do consumo dominante" (BRÜGGER, 2004, p. 99). Assim, é fundamental a reflexão sobre quais os objetivos da abordagem, quem são os estudantes e qual a crítica que se pretende realizar com a atividade.

Diversas propostas isoladas com o intuito de promover a EA são comuns aos professores e rotineiras nas escolas. As visitas de campo podem ser caracterizadas como uma dessas ações e são utilizadas pelos docentes como instrumento de sensibilização dos estudantes às temáticas ambientais e a observação dos problemas envolvidos nesse contexto, como demonstra a resposta do participante a seguir:

[...] Uma delas foi a visita em um aterro sanitário. Vimos ali como podemos diminuir o impacto sobre nosso planeta, além de criarmos uma maior consciência. O lixo, na verdade, não é lixo, mas sim recurso(s) ricos e reutilizáveis, que servem para infinitas outras aplicações (PARTICIPANTE H).

Assim, saídas a campo necessitam ter como propósito a percepção do todo, havendo necessidade de contextualizar o ambiente estudado com os conteúdos escolares, e a inserção do estudante como parte do ambiente e do processo educacional. A visitação a um determinado espaço terá maior efeito na aprendizagem se for pensada por meio de um olhar pedagógico. 
Palestras informativas também citadas pelos participantes e contempladas nesta categoria, como mencionado pelo Sujeito $\mathrm{O}$, "[...] palestras explicando como não desperdiçar água em casa, como usar a energia elétrica racionalmente e também um pouco sobre separação do lixo". Atividades como palestras, descoladas de um contexto desenvolvido ou de algum propósito requerido pelos docentes caracterizam apenas atividades com caráter tapa furo, não despertando qualquer sentimento ou interesse por parte dos educandos. Tais atividades tornam-se ainda mais comuns na culminância de datas destaque como "Semana do Meio Ambiente" ou "Semana da Água”. Vale frisar que, embora estas atividades citadas fazerem parte de um contexto maior nas instituições de ensino, a abordagem que muitas vezes são realizadas trazem esse caráter pontual, fragmentado e caricaturizado.

De acordo com Guimarães (2004a), as atividades pedagógicas devem superar a transmissão de conhecimentos ecologicamente corretos, bem como as ações de sensibilização com o propósito de atrair pela afetividade dos estudantes para causas ambientais. Deve-se ir além, aproximando esses fatos de um contexto crítico no processo educativo.

Para Layrargues (2006), o sistema de ensino exerce um poder sobre o destino das pessoas, pois se passa em média um terço da vida dentro de instituições de ensino. Nessa perspectiva, Morin (2000) afirma que a educação deve estimular a capacidade natural da mente em resolver problemas e saber relacioná-los com a totalidade. Assim, ao pensar na resolução de problemas ambientais faz com que o indivíduo se empenhe em adquirir novos conhecimentos em diferentes campos do saber, buscando soluções aos problemas analisados e, assim, constituindo novas aprendizagens. De acordo com Jacobi (2005), Guimarães (2004a) e Sauvé (2005), a abordagem ambiental conservadora, tal como as apresentadas nas práticas dos participantes descritas nessa categoria, parece fundamentar-se numa visão reformista, na qual predominam ações pontuais, apresentando questões ambientais descontextualizadas dos temas geradores, mantendo uma visão pedagógica simplista e reducionista. Esta visão demonstra fragilidade, pois ao longo do tempo, as pessoas passaram a não se contentar mais com respostas simplistas para problemas complexos, conduzindo a uma forma intrincada de pensamento e a busca por soluções aos problemas atuais.

Para a solução dessas situações, faz-se necessária uma visão inter e transdisciplinar (JACOBI, 2005; LIMA, 2002; LOUREIRO, 2004). Japiassu (2006, p. 31) afirma que "conhecer o todo não é obtido pela soma das partes", sendo assim, compreende-se que os elementos do conhecimento só possuem sentido pelas relações recíprocas que mantém entre si, resultado da interação de vários fatores.

A busca de uma EA que realmente ultrapasse ações ineficazes realizadas na escola perpassa a EA recebida por aqueles as organizam. Dessa forma, é relevante que nos espaços 
educativos frequentados pelos professores ainda em formação e aqueles que já tem uma trajetória profissional consolidada sejam colocados a pensar, primeiramente em suas concepções, para que avancem na prática de ensino dos seus estudantes.

\section{Considerações Finais}

Analisando as diversas práticas narradas pelos participantes dessa pesquisa, constatou-se que ainda é difícil para o licenciado a inserção da temática ambiental, de modo que leve o estudante a uma reflexão sobre os problemas ambientais e seu papel na busca por soluções. Foram descritos projetos realizados de acordo com a demanda escolar na ocasião e, comumente, trabalhos relacionados a determinadas datas alusivas a temas ambientais ou seguindo o calendário letivo previamente determinado por outros.

Atividades pertinentes às questões levantadas pelos alunos ou problemas relacionados a questões ambientais que norteiam o ambiente onde a escola está inserida não foram observados nos relatos desses participantes de pesquisa. Constata-se, desta forma, a maneira imposta da construção de projetos, não relacionando as reais possibilidades a serem exploradas a partir da EA, como elementos de conexão entre os conteúdos e disciplinas. Houve o predomínio de uma concepção conservadora referente à EA o que justifica e garante a perpetuação destes modelos de ações.

Os trabalhos realizados são válidos do ponto de vista da transversalidade, porém, quanto ao exercício da cidadania, tornando o estudante um sujeito crítico diante ao que se enfrenta, não confere a ele o verdadeiro empoderamento para que as mudanças desejadas sejam realmente possíveis. Isso corrobora a uma vasta bibliografia que aponta a uma falta de reflexão não somente do professor, mas da escola quanto aos objetivos. Nesse sentido, o poder de alcance das atividades faz com que a atividade não atinja o seu real potencial, estando sujeitas a distorções ou afastamentos dos problemas ambientais de viés crítico.

Aos professores se justifica sua pouca intimidade à temática ambiental devido à falta de formação, a qual está descrita como dever do Estado desde o estabelecimento da Constituição Federal em 1988. Sabe-se das carências, das tantas obrigações a serem cumpridas pelo docente,

porém, tratar de assuntos relacionados ao ambiente é tratar do próprio cotidiano, enquanto cidadão do mundo e pesquisador de si mesmo, necessitando de disposição à tarefa e a aprender.

A invisibilidade garantida à EA pela BNCC não pode ser um imobilizador às ações da escola na promoção de um ambiente saudável e na promoção de ações voltadas à sustentabilidade. Currículos são intencionais, dotados de escolhas, portanto, torna-se necessário refletir e construir o documento que melhor representa seu grupo, dotando-o de criticidade e 
envolvendo a escola e comunidade, envolvendo todos os indivíduos na solução dos problemas ambientais locais.

É necessária uma mudança na forma como o professor dimensiona o problema, na forma como expõe a situação, colocando o estudante como protagonista, contextualizando o ensino, buscando aproximar as questões ambientais que norteiam o estudante do que objetiva em suas práticas educativas. Porém, este tipo de medida ainda é um obstáculo, pois cabe ao professor uma mudança em seus conceitos, implicando na forma como ele foi condicionado a pensar ainda quando estudante, em igual situação dos seus atuais alunos.

\section{Referências}

ALMEIDA, Teresa Joelma Barbosa. Abordagem dos temas transversais nas aulas de ciências do ensino fundamental, no distrito de Arembepe, município de Camaçari-BA. Candombá Revista Virtual, v. 2, n. 1, p 1-13, 2006.

ANDRADE, Maria Carolina Pires de; PICCININI, Cláudia Lino. Educação Ambiental na Base Nacional Comum Curricular: retrocessos e contradições e o apagamento do debate socioambiental. IX EPEA Encontro Pesquisa em Educação Ambiental. Juiz de Fora - MG. 2017. p.1-13. Disponível em: http://epea.tmp.br/epea2017_anais/pdfs/plenary/0091.pdf. Acesso em: 10 de mai. 2019.

BEHREND, Danielle Monteiro; COUSIN, Cláudia da Silva; GALIAZZI, Maria do Carmo. Base Nacional Comum Curricular: o que se mostra de referência à Educação Ambiental? Ambiente \& Educação, v. 23, n. 2, p. 74-89, 2018.

BORGES, Regina Maria Rabello; BASSO, Nara Regina de Souza; ROCHA FILHO, João Bernardes da. Desafios da realização da transdisciplinaridade da educação básica em ciências e matemática. In: BORGES, R. M. R.; BASSO, N. R. S.; ROCHA FILHO, J. B. R. (Org.) Propostas interativas na educação científica e tecnológica. Porto Alegre: EDIPUCRS, 2008. p.13-22.

BRÜGGER, Paula. Educação ou adestramento ambiental? $3^{\mathrm{a}}$ ed. Florianópolis: Letras contemporâneas, 2004.

BRASIL. Lei 9.394, de 20 de dezembro de 1996. Lei de Diretrizes e Bases da Educação Nacional. Brasília, $1996 . \quad$ Disponível em: <https://www2.senado.leg.br/bdsf/bitstream/handle/id/70320/65.pdf>. Acesso em: 25 ago. 2019.

BRASIL. Lei n. 9795 - 27 de abril de 1999. Dispõe sobre a educação ambiental. Política Nacional de Educação Ambiental. Brasília, 1999. Disponível em: <https://www.mma.gov.br/estruturas/educamb/_legislacao/20_legislacao18032009111654.pdf>. Acesso em: 25 ago. 2019.

BRASIL. Ministério da Educação. Diretrizes Curriculares Nacionais Gerais da Educação Básica. Brasília: MEC, 2013.

BRASIL. Base Nacional Comum Curricular: educar é a base. Brasília: MEC/CONSED/UNDIME, $2017 . \quad$ Disponível em: $\langle$ http://basenacionalcomum.mec.gov.br/images/BNCC_EI_EF_110518_versaofinal_site.pdf $>$. Acesso em: 14 abr. 2019.

CARVALHO, Isabel Cristina de Moura. Educação Ambiental e a formação do sujeito ecológico. $6^{\text {a }}$ ed. São Paulo: Cortez, 2012. 
FREIRE, Paulo. Pedagogia da Autonomia: saberes necessários à prática educativa. $21^{\mathrm{a}}$ ed. São Paulo: Paz e Terra, 1996.

GUIMARÃES, Mauro. Educação Ambiental Crítica. Identidades da Educação Ambiental Brasileira, Brasília, 2004a.

GUIMARÃES, Mauro. Educação Ambiental: no consenso um embate? $2^{\mathrm{a}}$ ed. Campinas: Papirus, 2004b.

GUIMARÃES, Mauro. Educação Ambiental: participação para além dos muros da escola. In: MELLO, S. S.; TRAJBER, R. (coord.). Vamos cuidar do Brasil: conceitos e práticas em educação ambiental na escola. Brasília: Unesco, 2007. p. 85-94.

JACOBI. Pedro Roberto. Educação Ambiental: o desafio da construção de um pensamento crítico, complexo e reflexivo. Educação e Pesquisa, v. 31, n. 2, 2005, p. 233-250.

JAPIASSU, Hilton. O sonho Transdisciplinar: e as razões da filosofia. Rio de Janeiro: Imago, 2006.

LAYRARGUES, Philippe Pomier. Muito além da natureza: educação ambiental e reprodução social. In: Loureiro, C. F. B.; Layrargues, P. P.; Castro, R. C. (Org.) Pensamento complexo, dialética e educação ambiental. São Paulo: Cortez, 2006. p. 72-103.

LIMA, Gustavo Ferreira da Costa. Crise ambiental, educação e cidadania. In: LAYRARGUES, P. (Org.). Educação Ambiental: Educação ambiental repensando o espaço da cidadania. São Paulo: Cortez, 2002.

LOUREIRO, Carlos. Trajetória e fundamentos da educação ambiental. São Paulo: Cortez, 2004.

MORIN, Edgar. Os Sete saberes necessários à educação do futuro. Brasília, DF: UNESCO, 2000 .

MORAES, Roque; GALIAZZI, Maria do Carmo. Análise textual discursiva. $2^{\text {a }}$ ed. Ijuí: Editora UNIJUÍ, 2013.

MOREIRA, Antônio Flávio; TADEU, Tomaz. Sociologia e teoria crítica do currículo: uma introdução. In: MOREIRA, A. F.; TADEU, T. (Org.) Currículo, cultura e sociedade. 12. ed. São Paulo: Cortez, 2011. p. 13-48.

RICARDO, Élio Carlos. Educação CTSA: obstáculos e possibilidades para sua implementação

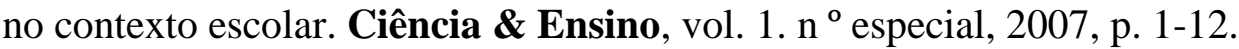

SAUVÉ, Lucie. Uma cartografia das correntes em educação ambiental. In: SATO, M.; CARVALHO, I. Educação Ambiental: pesquisa e desafios. Porto Alegre: Artmed. 2005. p.1744.

Recebido em 22/05/2020 - Aprovado em 30/06/2020. 